\title{
Cyanobacterial blooms cause heating of the sea surface
}

\author{
Mati Kahru ${ }^{1}$, Juha-Markku Leppänen ${ }^{2}$, Ove Rud ${ }^{1}$ \\ ${ }^{1}$ Stockholm University, Department of Physical Geography, S-106 91 Stockholm, Sweden \\ ${ }^{2}$ Finnish Institute of Marine Research, PO Box 33, SF-00931 Helsinki, Finland
}

\begin{abstract}
A series of AVHRR (Advanced Very High Resolution Radiometer) satellite images and simultaneous ship transects in July 1992 were used to show that surface accumulations of cyanobacteria (blue-green algae) in the southern Baltic Sea can cause local increases in the satellite-derived sea surface temperature (SST) by up to $1.5^{\circ} \mathrm{C}$. The warmer SST is attributed to increased absorption of sunlight due to increased phytoplankton pigment concentration. The distribution of surface cyanobacterial accumulations detected as increased reflectance in the visible channel of the AVHRR satellite sensor was correlated with chlorophyll concentration at $5 \mathrm{~m}$ depth. Warm SST anomalies ('hot spots') appeared both in accumulations of surface-floating cyanobacteria and in areas of high chlorophyll concentration (detected by shipboard measurements). The 'hot spots' followed the detailed boundaries of the cyanobacterial plumes and probably represented a shallow, diumally heated top layer that appeared by afternoon in conditions of low wind $\left(2 \mathrm{~m} \mathrm{~s}^{-1}\right)$ and weak mixing, disappeared during the night due to thermal convection and were hardly detectable on days with wind speed of 6 to $8 \mathrm{~m} \mathrm{~s}^{-1}$. The vertical extension of the top diurnally heated layer was probably less than $1 \mathrm{~m}$ and definitely less than $5 \mathrm{~m}$, at which depth no temperature increase was detected. It is suggested that the day/night SST difference in low-wind conditions may be an indicator of near-surface phytoplankton pigment concentration.
\end{abstract}

\section{INTRODUCTION}

Marine biologists have long tried to understand how physical forcing affects biological processes in the ocean. The converse, cases where biological processes directly influence ocean physics, has been much more difficult to observe and quantify. Sunlight penetrating the sea surface is eventually either absorbed and converted to heat, backscattered out of the water, or consumed by phytoplankton in photosynthesis. All of these processes are influenced by the concentration of plankton and other suspended and dissolved optically active matter in the top layer of the ocean. Lewis et al. (1990) and Sathyendranath et al. (1991) have shown that on basin-wide scales optical properties of the ocean, which are mainly determined by the concentration of phytoplankton pigments, significantly affect the sea surface temperature (SST) and the heat budget of the upper mixed layer. On smailer scales the influence of biological variables on ocean physics is less evident. Nevertheless, Ramp et al. (1991) have observed patch- iness in near-surface thermal stratification on scales of 5 to $10 \mathrm{~km}$, which they attributed to increased light absorption by near-surface chlorophyll patches. They were able to model the observed vertical thermal structure by assuming increased light absorption due to increased chlorophyll concentration at constant albedo

With increased backscattering of light at the sea surface, increase in SST becomes less likely as less radiant energy is available in the water. Near-surface accumulations of cyanobacteria (blue-green algae) are an example of a phenomenon that can be detected by increased reflectance (albedo), even using lowsensitivity satellite sensors. In the Baltic Sea regularly occurring toxic cyanobacterial blooms pose a major environmental and even health hazard (for a recent review see Kononen 1992). The conspicuous surface accumulations are known to be formed by the diazotrophic, filamentous Nodularia spumigena. Surface cyanobacterial accumulations in the Baltic Sea have occasionally been observed on various satellite images 
(Horstmann 1983, 1988, Horstmann et al. 1986); however, no systematic study has been conducted so far.

Below we present observations using Advanced Very High Resolution Radiometer (AVHRR/2) images as well as continuous ship sampling transects to show that in spite of the increased albedo - i.e. decreased radiant energy entering the water column - in lowwind conditions, cyanobacterial plumes cause increases in SST by up to $1.5^{\circ} \mathrm{C}$ due to increased light absorption and the formation of a shallow diurnal thermocline in the top $1 \mathrm{~m}$. The increased light absorption is attributed to the increased concentration of phytoplankton pigments covarying with the surface-floating accumulations.

\section{OBSERVATIONS AND METHODS}

Satellite data from the AVHRR/2 scanner flying on the National Oceanic and Atmospheric Agency satellite NOAA-11 were used. The images were corrected for geometric distortion and registered to the Albers equal area projection with a spatial resolution of $1.1 \mathrm{~km}$ (G. R. Rosborough, D. Baldwin \& W. J. Emery

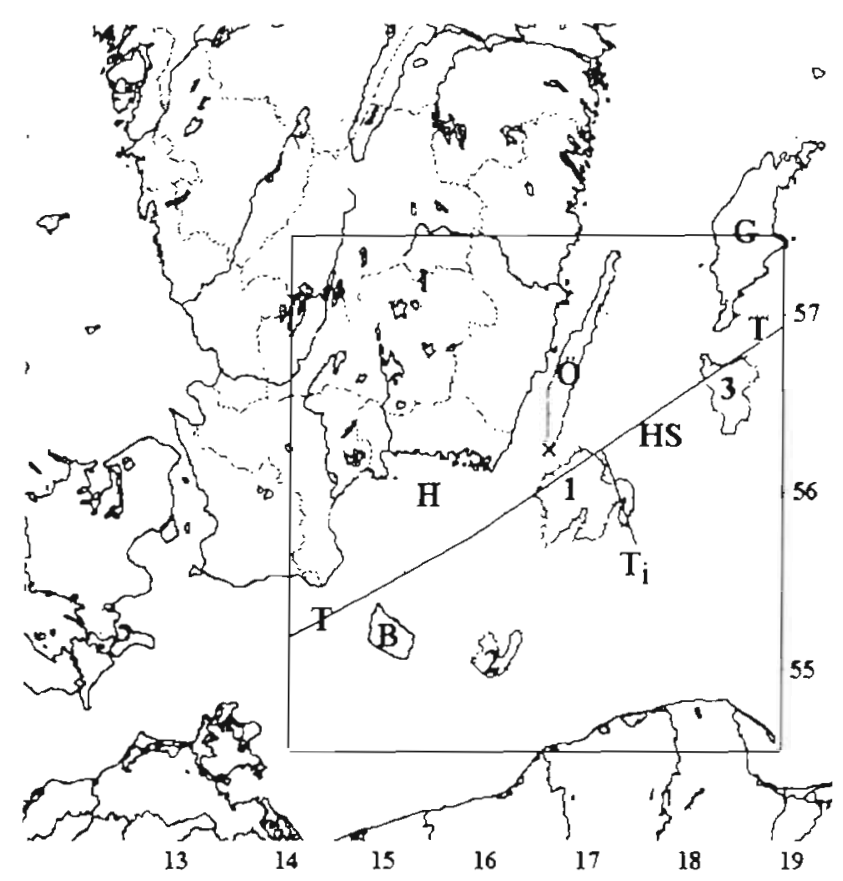

Fig. 1. Location of the study area in the southern Baltic Sea. The box shows the area covered by the images in Fig. 2 Outlined are the dense cyanobactenal accumulations $(1,2,3)$, SST 'hot spot' without a corresponding reflectivity increase (HS), 'Finnjet' transect (T), an irnaginary transect across one of the dense accumulations $\left(T_{1}\right)$, the islands of Gotland $(G)$, Olland $(O)$ and Bornholm $(B)$, Hano Bight $(H)$, and the location of wind measurements ( $\mathrm{x}$ ) at Ölands Södra Grund unpubl.). The precise location of each image was checked and if necessary adjusted in relation to the coastline map of the area. Channel 1 visible radiation $(0.58$ to $0.68 \mu \mathrm{m})$ data were converted to albedo (percent reflectance). Channel 4 thermal infrared (10.3 to $11.3 \mu \mathrm{m}$ ) data were converted to radiance temperature using in-flight calibration with non-linear corrections (Weinreb et al. 1990).

A series of sufficiently cloud-free images were recorded during the cyanobacterial bloom in the southern Baltic Sea in July 1992. The following NOAA-11 passes were used. July 7 (UTC 13:28 h), July 8 (03:27 and 13:23 h), July $9(03: 15$ and 13:04 h). (The early morning passes were at about 04:00 h local time and the afternoon passes at about 14:00 h local time.) The study area with points of reference is shown in Fig. 1.

Three-hourly wind recordings at Ölands Söra Grund (see Fig 1) were provided by the Swedish Meteorological and Hydrological Institute.

Shipboard sampling was carried out unattended onboard the ferry 'Finnjet' which plies between Helsinki, Finland, and Travemünde, Germany. Surface chlorophyll a fluorescence (Turner Designs flowthrough fluorometer), temperature and salinity (Aanderaa thermosalinograph) were recorded by pumping water through a series of sensors while the ship steamed at an average speed of 25 knots. The water intake was situated below the ship hull at ca $5 \mathrm{~m}$ depth. The frequency of measurements was $10 \mathrm{~s}$, allowing a spatial resolution of ca $125 \mathrm{~m}$. The fluorescence values were converted to chlorophyll a concentrations by an empirical equation obtained by correlating simultaneous measurement of fluorescence and chlorophyll a values using the extraction technique described in Helsinki Commission (1988). An ISCO automatic sampler was used to collect the water for calibrations.

\section{RESULTS}

Regions of increased reflectance in the visible spectrum with a characteristic spatial structure (texture) revealed surface accumulations of cyanobacteria Nodularia spumigena that covered large areas in the southern Baltic Sea at the beginning of July 1992. The key observation that prompted the following analysis was the close resemblance between the patterns of cyanobacterial accumulation and that of SST on the July 8 afternoon image (Fig. 2). The increase in SST in dense accumulations compared to neighboring areas was approximately $1.5^{\circ} \mathrm{C}$. The 3 densest accumulations have been contoured in Fig. 1. The total area covered by cyanobacterial accumulations was nearly $7000 \mathrm{~km}^{2}$ in the Hanö Bight area [including the most conspicuous Patch 1, Patch 2 (connected with Patch 1 


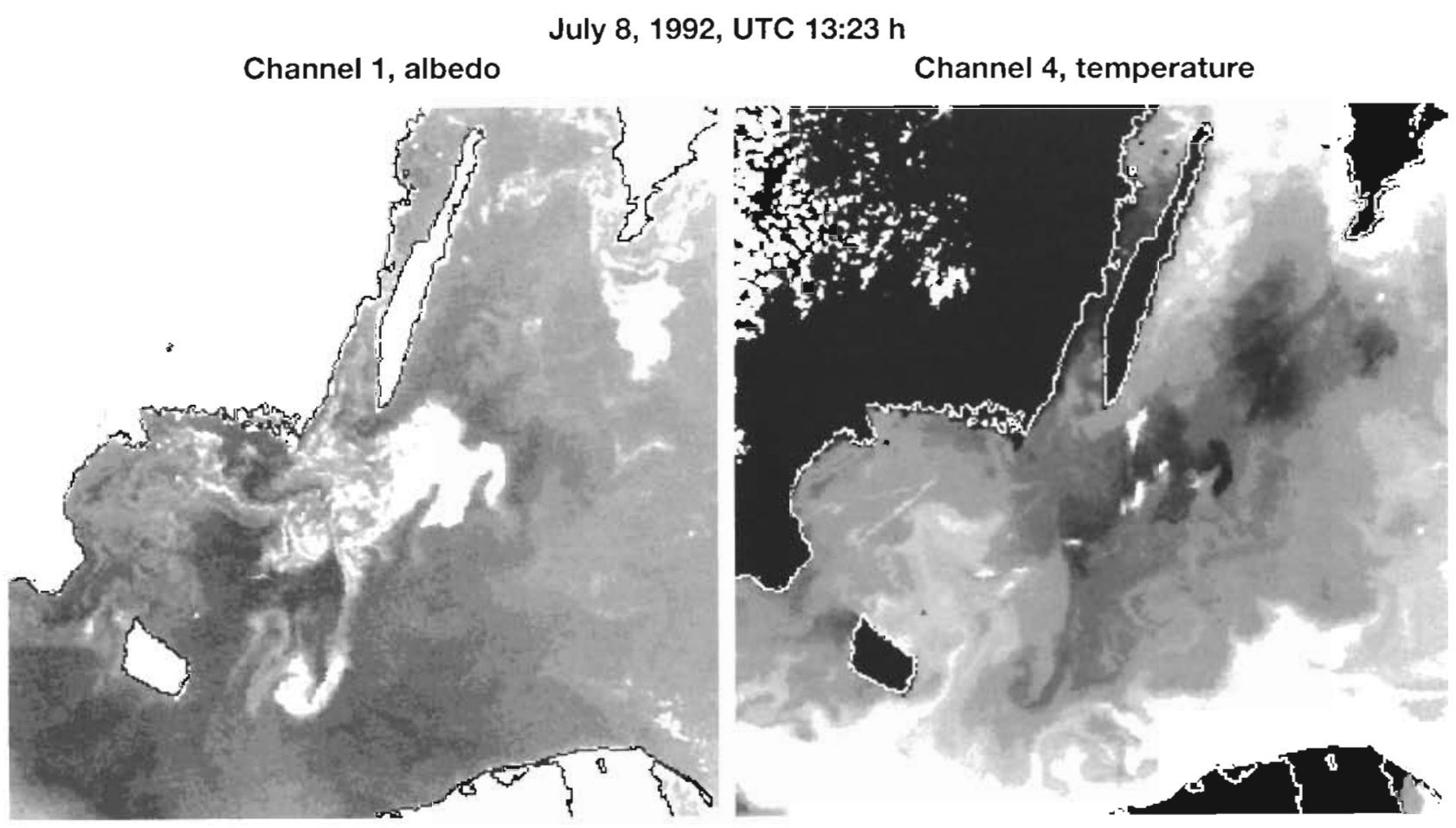

Fig. 2. NOAA-11 AVHRR images of Channel 1 albedo and Channel 4 temperature in the southern Baltic Sea, with surfacefloating cyanobacterial accumulations. Coastlines have been overlaid with black (Channel 1) or white (Channel 4) contours Lighter shades of gray represent higher aibedo values and lower temperatures

via a jet-like feature) plus the less dense structures all over the Bight] and nearly $1000 \mathrm{~km}^{2}$ south of Gotland (Patch 3). On the SST image the cyanobacterial patches are well recognizable as 'hot spots' due to their higher temperatures compared to the surrounding areas. In addition, another 'hot spot' area without a corresponding cyanobacterial accumulation at the surface was located between Patches 1 \& 3 (Fig 2). A feasible explanation for this is given below. An extensive band of cool water, the result of previous upwelling, is visible along the southern part of the image off the coast of Poland. Filaments of the cool upwelled water can be seen spreading from coasts into the central basin (e.g. southeast of Bornholm). The surface water in the low-reflectance area between Bornholm and Patches 1 \& 2 might have originated from the upwelled water in the south. If that is true then the upwelled water had to be low in nutrients or otherwise less suitable for phytoplankton growth, as even the chlorophyll a concentration in this water was lower $\left(2 \mathrm{mg} \mathrm{m}^{-3}\right.$ vs 2.5 to $3 \mathrm{mg} \mathrm{m}^{-3}$; see Fig. 5). No simultaneous nutrient data are available, but a few days later (July 12) nitrate concentrations were below the detection limit and phosphates were at 0.06 to $0.07 \mu \mathrm{mol} \mathrm{l}^{-1}$ along the 'Finnjet' track between Bornholm and Gotland ( 7 uniformly spaced samples). A few small scattered clouds covered small parts of the dense Patch 1 as can be seen by their cold signatures on the SST image. To visualize this another way, we plotted an imaginary transect across the dense surface accumulation (Fig. 3). The close covariance between the SST and albedo is obvious. The early morning SST images on preceding and succeeding mornings did not show any of the accumulation-related structures visible on the July 8 afternoon image. This indicates that the SST patterns had been destroyed by convective cooling during the night. The difference in SST between the afternoon image on July 8 and that the next morning was, on average, $1.5^{\circ} \mathrm{C}$, a value similar to the difference between the 'hot spot' and neighboring areas. Afternoon images on previous and subsequent days (not shown), although not as cloud-free as on July 8, showed that cyanobacterial Patches $1 \& 2$ (but not Patch 3 ) were present with sinilar albedo levels and in similar shapes, at least during the period July 7 to 9 . However, it is clear that the close correlation between patterns of visible reflectance and SST was not present on the other days. On the afternoon image of July 9 the correlation is only marginally visible (Fig. 3). A probable explanation for this is provided by the wind speed record from a nearby coastal location (Fig. 4). It can be seen that the July 8 image was recorded after a period of low wind speed $\left(2 \mathrm{~m} \mathrm{~s}^{-1}\right)$ whereas on July 7 and 9 the wind speed was 6 to $9 \mathrm{~m} \mathrm{~s}^{-1}$. We can therefore conclude that the warm 
July 8,1992 , UTC 13:23 h

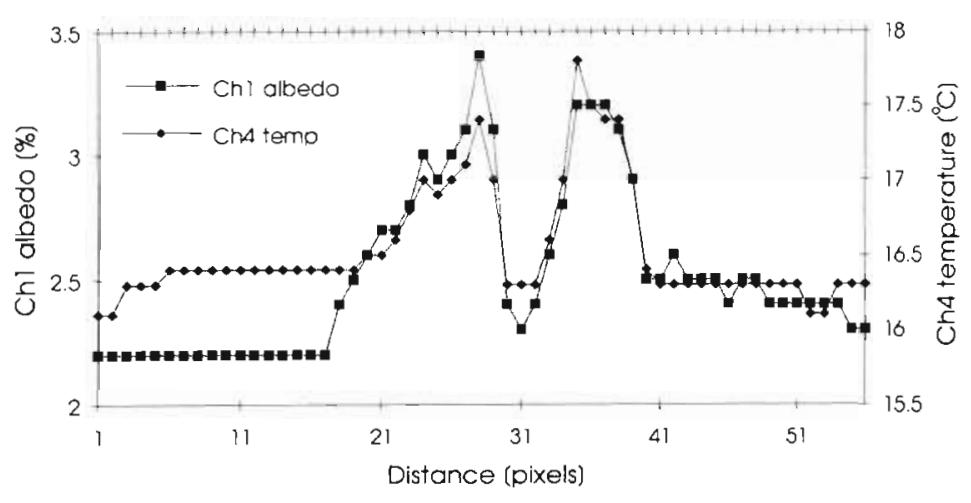

July 9, 1992, UTC 13:04 h

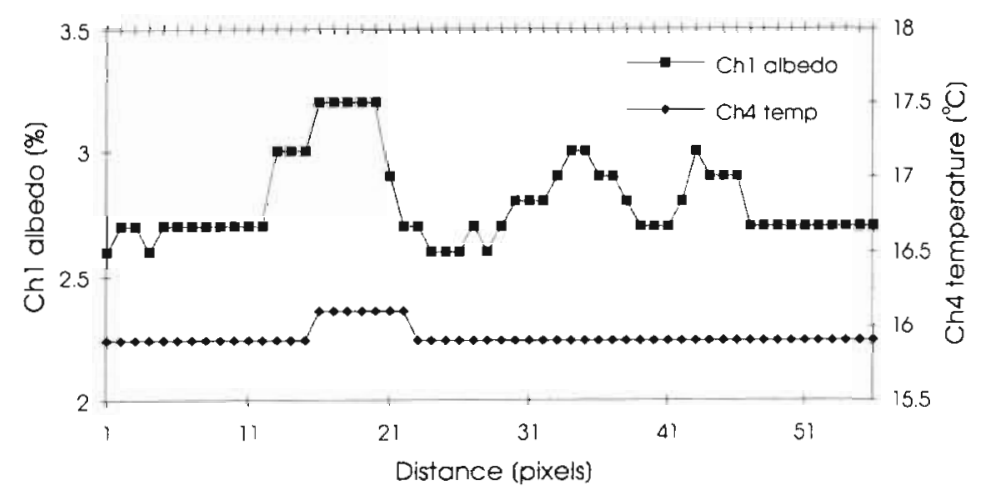

Fig. 3. Transect (NNW to SSE) across a dense cyanobacterial accumulation showing (upper) covariance of the surface accumulation of cyanobacteria (reflectivity expressed as albedo) and sea surface temperature on July 8 , and (lower) the loss of covariance on July 9 . The location of the transect is shown as $T_{1}$ in Fig. 1

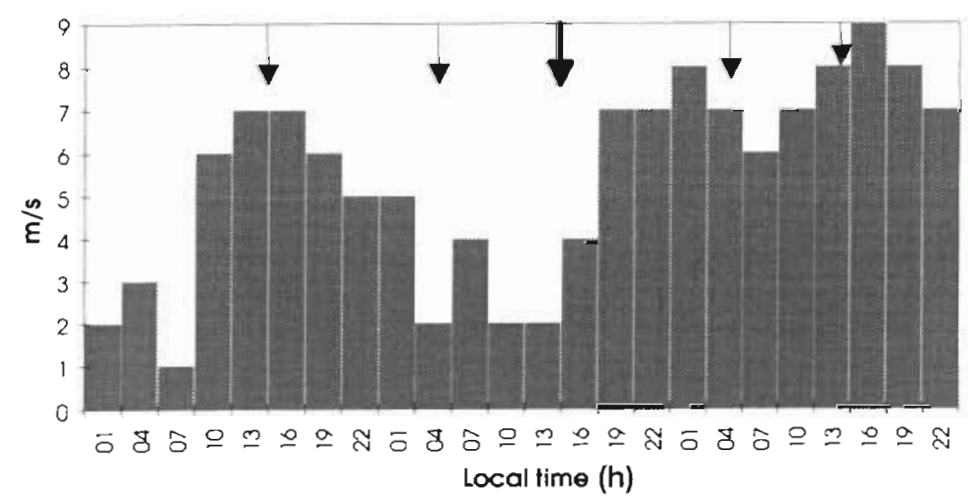

Fig. 4. Wind speed at Olands Södra Grund during July 7 to 9, 1992. Times of the satellite passes (in local time) are shown as arrows. The heavy arrow in the middle corresponds to the image in Fig. 2 where the most significant temperature increase occurred after a period of low wind speed
SST patterns related to cyanobacterial accumulations appeared at low wind speed, were destroyed at night and did not appear at wind speeds of 6 to $9 \mathrm{~m} \mathrm{~s}^{-1}$.

A general covariance between the satellitederived reflectance and continuous shipboard recording of chlorophyll a concentration at $5 \mathrm{~m}$ depth was evident at least locally (Fig. 5). The part of the ship transect shown was covered between UTC 7:20 and 10:20 h whereas the NOAA pass was recorded at UTC 13:23 h.

As expected, nighttime SST measurements displayed better qualitative correspondence with the shipboard recorded temperature at $5 \mathrm{~m}$ than did the afternoon-recorded SST which showed the significant surface heating effects ('hot spots') (Fig. 6). The significant difference between the shipboard-measured values of temperature and the satellitederived SST (actually the AVHRR Channel 4 radiance temperature) is due to the fact that no attempt was made to calculate the multichannel SST as this is known to increase the pixel-to-pixel noise (Minnett 1991). No temperature increase corresponding to the surface 'hot spots' could be observed at a depth of $5 \mathrm{~m}$. The shipborne chlorophyll transect provided an explanation for the SST 'hot spot' without a corresponding surface reflectance increase (Fig. 6). It appeared to coincide with a 2-fold increase in the chlorophyll a concentration at $5 \mathrm{~m}$ (and probably above it) that had obviously caused increased absorption of radiant energy and heating of the sea surface. Inherent timing errors between a satellite image taken over 1.5 min and a ship transect recorded over many hours, as well as different spatial averaging $\left(\mathrm{km}^{2}\right.$ pixel size of the AVHRR image vs recording along a narrow line), preclude a perfect match between the ship and satellite measurements. Nevertheless, it is clear that the major source of discrepancy between the afternoon SST and temperature at $5 \mathrm{~m}$ was the near-surface temperature stratification that appeared during the day in conditions of low wind speed and strong insolation.

\section{DISCUSSION}

When observing covarying mesoscale distributions of a physical variable such as temperature and a biological variable such as 
phytoplankton concentration, it is usually very difficult to infer any causal relationships between the two. The first possibility - that temperature differences cause the biological response - is usually not the case, as the range of temperature variability in the open ocean at mesoscales is not large enough to produce a direct change in the intensity of biological processes. Instead, the covariability usually reflects the different origins and mixing of water masses. Upwellings and upwelling filaments of colder and nutrientrich water are good examples of situations in which the covariability is almost always present but may be either negative (low phytoplankton concentration in cold, recently upwelled water) or positive (high phytoplankton concentration as a result of rapid growth at high nutrient levels). Another example is the covariability of temperature and chlorophyll during the early spring bloom period in the Baltic Sea, which led many investigators (e.g. Kaiser \& Schultz 1978) to believe that the formation of thermal stratification causes the start of the phytoplankton spring bloom. In fact, as was established later (Kahru \& Nômmann 1990), both the increased temperature and chlorophyll reflected the reduced vertical mixing caused not by thermal but by saline stratification due to spreading of coastal filaments, eddies, interleaving of water masses, etc.

In this paper we have shown a case when a biological variable, i.e. concentration of surface-floating cyanobacteria, was well correlated with patterns of afternoon SST increase. Compared to the 'bulk' water temperature at the depth of one or a few meters, the satellite-derived SST is influenced by both the cool 'skin effect' in the top millimeter and the diurnal thermocline in the top meter (e.g. Minnett 1991). The increase of SST in cyanobacterial accumulations by $1.5^{\circ} \mathrm{C}$ was probably caused by a shallow top layer of the sea absorbing more solar radiation due to an elevated absorption coefficient. The heat budget of the ocean's surface can be formulated as follows:

$$
Q_{0}=(1-\alpha) Q_{\mathrm{S}}+Q_{\mathrm{L}}-Q_{\mathrm{EH}},
$$

where $Q_{0}=$ net heat flux; $\alpha=$ albedo for the shortwave flux $Q_{S} ; Q_{L}=$ net longwave flux; and $Q_{E H}=$ net effect of evaporative/latent and sensible heat flux. As one would expect for the latitude, season, and conditions (midday, clear sky and light winds) in this study (see
Finnjet/NOAA July 8, 1992

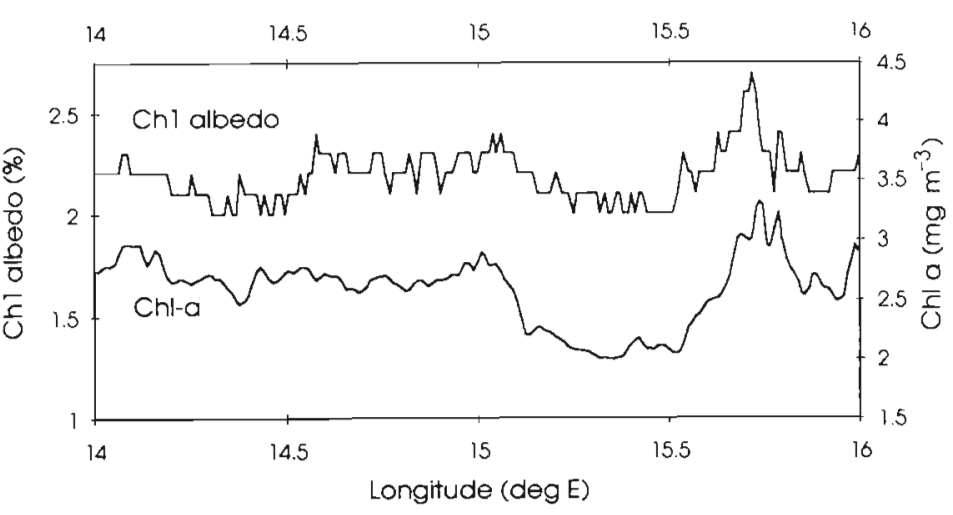

Fig. 5. Comparison between AVHRR-derived albedo and ship-recorded chlorophyl a concentration at $5 \mathrm{~m}$ depth on part of the 'Finnjet' transect (see Fig. 1)

Finnjef /NOAA July 8, 1992

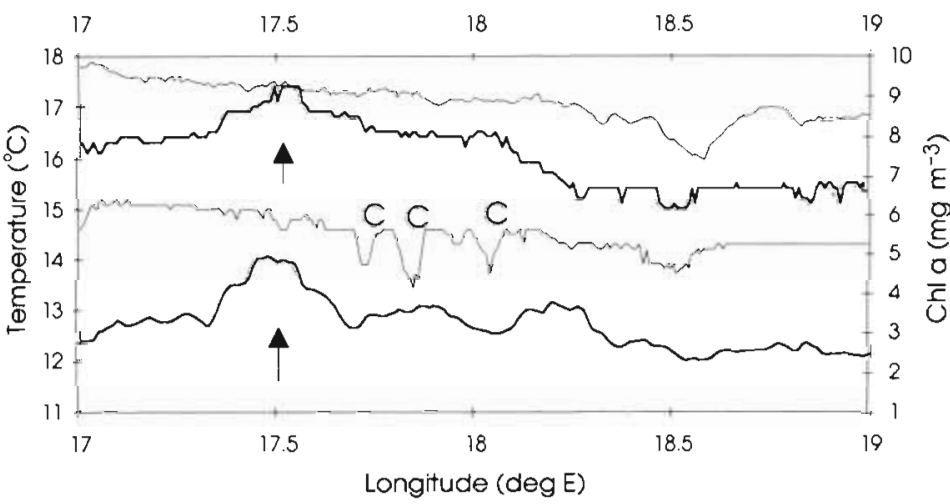

Fig. 6. Comparison among (curves from top down): ship-recorded temperature at $5 \mathrm{~m}$, AVHRR Channel 4 derived afternoon SST, AVHRR Channel 4 early morning SST, and ship-recorded chlorophyll a concentration along part of the 'Finnjet' track (see Fig. 1). Clouds in the early morning SST are marked with ' $\mathrm{C}$ ' Arrows point to the afternoon SST 'hot spot' presumably caused by the increased near-surface chlorophyll a concentration

e.g. Ramp et al. 1991), the net heat flux is dominated by the shortwave solar insolation $\left(Q_{S}\right)$ accounted for by the albedo $\alpha$. In their model, Ramp et al. (1991) used a constant albedo and increased the light extinction coefficient 6 -fold over the baseline in order to reproduce the observed patchiness of surface stratification in the California Current. In our case the increased albedo due to cyanobacteria at the surface had in fact the effect of reducing the amount of radiant energy entering the water. However, the reduction in the amount of available energy was obviously counteracted by a stronger effect of increased absorption by phytoplankton pigments and other associated sub- 
stances. The possibility that the water with higher temperature and that containing more cyanobacterial flakes had a common origin can be easily ruled out, as the elevated SST disappeared during the night, obviously due to convective cooling. The large diurnal variation in SST, i.e. the difference between afternoon and early morning SST values of more than $1^{\circ} \mathrm{C}$, is indicative of the formation of a shallow diurnal thermocline in the top several tens of centimeters (Stramma et al. 1986). On previous and subsequent days when the same cyanobacterial accumulations were present in similar form and intensity, the build-up of the top diurnal thermocline either was not observed or was only marginal due to stronger vertical mixing by wind action.

A similar increase of temperature in dense surface layers of cyanobacteria has been observed in Dutch freshwater lakes (Prangsma \& Roozekrans 1989); however, judging by their positive normalized difference vegetation index (NDVI) these floating algal 'mats' had to be much denser than the cyanobacteria observed here. NDVI is positive on vegetated surfaces and negative for water. The dense Nodularia accumulations discussed here had NDVI values below zero (up to -0.07 , a few isolated pixels up to 0.02 ) and were definitely too diffuse to be classified as vegetation.

Typical phytoplankton bloom concentrations in the ocean are far too low to be detected by the AVHRR sensor. It is therefore especially interesting that an SST 'hot spot' without cyanobacterial accumulations at the surface could be related to increased chlorophyll concentration at $5 \mathrm{~m}$. It is possible that SST 'hot spots' are an indicator of higher near-surface phytoplankton concentration. 'Hot spots' are a regular feature on AVHRR images of the Baltic Sea in low-wind conditions; however, the phenomenon has been studied very little. The 'hot spots' characteristically appear as patches with diffuse boundaries which evidently mask the spatial structure of the underlying temperature field. The factor most influential in causing the 'hot spots' is probably the submesoscale variability of the surface wind stress. However, quantification of this factor is very difficult experimentally. The diurnal SST difference that was used as an indicator of 'hot spot' intensity has also been used by Yan et al. (1990) to estimate the mixed layer depth

In conclusion, we have presented evidence that the cyanobacterial plumes in the southern Baltic Sea in low-wind conditions were instrumental in intensifying a shallow diurnal thermocline that resulted in local SST increases by about $1.5^{\circ} \mathrm{C}$. However, the question as to what had caused the appearance of the cyanobacterial plumes themselves at that time, and at these locations, remains open. It is generally believed (e.g. Horstmann 1975, Kononen 1992) that Nodularia blooms in the Baltic Sea are initiated if sufficient phosphorus is available and the water temperature exceeds $16^{\circ} \mathrm{C}$. These conditions, even if generally valid, are hardly sufficient to predict or model the actual bloom areas. Nodularia, being able to fix molecular nitrogen, has a competitive advantage over other phytoplankton in phosphorus uptake. As phosphate levels a few days after the conspicuous surface accumulations were still in the range of average pre-bloom concentrations for the Baltic (Kononen 1992), phosphorus was probably not a crucial factor causing the observed cyanobacterial bloom. During some stage of the bloom, the Nodularia filaments lose their ability to remain in the water column and accumulate near the surface in a process of 'inverted sedimentation' (Horstmann et al. 1986). As high water temperatures in July-August usually coincide with high insolation and clear sky conditions, good satellite imagery of the blooms can be obtained. High solar insolation and strong near-surface stratification may be some of the factors causing 'inverted sedimentation'. As the presence of cyanobacteria near the surface further increases heating and stratification in the surface layer, a positive feedback loop is generated that results in the massive surface accumulations of cyanobacterial aggregations. It may be that the 'inverted sedimentation' stage indicates the end of the bloom when chlorophyll concentration is expected to decrease due to photo-oxidation and chemical degradation. That would ideally produce a negative correlation between the extent of surface accumulation and the water column chlorophyll concentration. However, at least on some scales we actually observed a positive correlation between water column chlorophyll and the surface accumulations of cyanobacteria. It is evident that our present knowledge is insufficient to understand the complicated interactions between biological and physical processes leading to toxic cyanobacterial blooms in the Baltic.

Acknowledgements. Part of the satellite data used here was recorded at the German Federal Maritime and Hydrographic Agency in Hamburg and was kindly made available to us by Ms Gisela Tschersich. The wind measurements were kindly provided by B. Hakansson. W. J. Emery and Dan Baldwin (University of Colorado, Boulder) graciously provided us with a copy of their navigation software and helped with countless consultations. This study was supported financially by the Swedish Space Board.

\section{LITERATURE CITED}

Helsinki Commission. (1988). Guidelines for the Baltic Monitoring Programme for the third stage. Part D. Biological determinants. Baltic Sea Env. Proc. 27D: 1-161

Horstmann, U. (1975). Eutrophication and mass occurrence of blue-green algae in the Baltic. Merentutkimuslait. Julk./Havsforskningsinst. Skr. 239: 83-90 
Horstmann, U. (1983). Distribution patterns of temperature and water colour in the Baltic Sea as recorded in satellite images: indicators of plankton growth. Ber. Inst. Meereskde Kiel 106: 1-147

Horstmann, U. (1988). Satellite remote sensing for estimating coastal offshore transports. In: Jansson, B.-O. (ed.) Coastal-offshore ecosystem interactions. Lecture Notes coast. estuar. Stud. 22: 50-66

Horstmann, U., van der Piepen, H., Barrot, K. W. (1986). The influence of river water on the southeastern Baltic Sea as observed by Nimbus 7/CZCS imagery. Ambio 15: 286-289

Kahru, M., Nômmann, S. (1990). The phytoplankton spring bloom in the Baltic Sea in 1985, 1986: multitude of spatiotemporal scales. Cont. Shelf Res. 10: 329-354

Kaiser, W., Schulz, S. (1978). On the causes for the differences in space and time of the commencement of the phytoplankton bloom in the Baltic. Kieler Meeresforsch., Sonderh. 4: 161-170

Kononen, K. (1992). Dynamics of the toxic cyanobacterial blooms in the Baltic Sea. Finn. mar. Res. 261: 3-36

Lewis, M. R., Carr, M.-R., Feldman, G., Esaias, W., McClain, C. (1990). Influence of penetrating solar radiation on the heat budget of the equatorial Pacific Ocean. Nature 347 : $543-545$

This article was submitted to the editor
Minnett, P. J. (1991). Consequences of sea surface temperature variability in the validation and application of satellite measurements. J. geophys. Res. 96: 18475-18489

Prangsma, G. J., Roozekrans, J. N. (1989). Using NOAA AVHRR imagery in assessing water quality parameters. Int. J. rem. Sens. 10: 811-818

Ramp, S. R., Garwood, R. W. Davis, C., Snow, R. L. (1991). Surface heating and patchiness in the coastal ocean off central California during a wind relaxation event. J. geophys. Res. 96: 14947-14957

Sathyendranath, S., Gouveia, A. D., Shetye, S. R., Ravindran, P., Platt, T. (1991). Biological control of surface temperature in the Arabian Sea. Nature 349: 54-56

Stramma, L., Cornillon, P., Weller, R. A., Price, J. F., Briscoe, M. G. (1986). Large diurnal sea surface temperature variability: satellite and in situ measurements. J. phys. Oceanogr. 16: 827-837

Weinreb, M. P., Hamilton, G., Brown, S., Koczor, R. J. (1990). Nonlinearity corrections in calibration of advanced very high resolution radiometer infrared channels. J. geophys. Res. 95: 7381-7388

Yan, X.-H., Schubel, J. R., Pritchard, D. W. (1990). Oceanic upper mixed layer depth determined from satellite data. Rem. Sens. Environ. 32: 55-74

Manuscript first received: May 28, 1993 Revised version accepted: July 30, 1993 